\title{
Visualização e Representação Geométrica com suporte na Teoria de Van Hiele
}

\author{
Visualization and Geometrical Representation supported in the Van Hiele Model \\ Marluce Trentin Oliveira ${ }^{1}$ e José Carlos Pinto Leivas ${ }^{2}$
}

${ }^{1}$ Mestre em Ensino de Matemática, Escola Básica de Santa Maria, Unifra, Santa Maria, Brasil marlucetrentino@hotmail.com

${ }^{2}$ Doutor em Educação, Programa de Pós-Graduação em Ensino de Ciências e Matemática, Unifra, Santa Maria, Brasil leivasjc@unifra.br

\section{Resumo}

Este artigo apresenta um recorte de uma dissertação de mestrado profissional, concluída pela primeira autora, sob a orientação do segundo, a qual teve por objetivo desenvolver percepção visual e raciocínio geométrico em alunos de um $5^{o}$ ano do Ensino Fundamental com suporte da Teoria de Van Hiele, na cidade de Santa Maria, RS. Trata-se de uma pesquisa qualitativa com um estudo de caso e se ancorou nessa teoria para o desenvolvimento do raciocínio em Geometria, cujo primeiro nível (visualização) é útil para a identificação de formas geométricas planas e espaciais. Além disso, visualização é habilidade e tema atual em pesquisas na Educação Matemática. O segundo nível (análise) juntamente com o primeiro, foram analisados em uma atividade em que a investigadora utilizou recursos materiais concretos para os alunos utilizarem o tato para identificar, classificar e representar formas geométricas planas e espaciais. Os resultados mostraram que os alunos conseguiram visualizar (como construto mental) as formas geométricas espaciais, que se encontravam em uma caixa opaca, apenas utilizando o tato. A partir disso, identificaram elementos planos e espaciais que as constituíam, nomearam os objetos e suas componentes e, posteriormente, fizeram as respectivas representações no plano. Concluiu-se que a atividade proporcionou um reconhecimento pela professora do nível inicial da teoria de Van Hiele - visualização ou reconhecimento- para alguns e desenvolvimento para outros, favorecendo o desenvolvimento do conteúdo programático da sérielano na sequência.

Palavras-chave: Raciocínio geométrico; Habilidades visuais; Geometria; Teoria de Van Hiele

\section{Abstract}

This article presents a part of a master professional dissertation, completed by the first author, under the guidance of the second, which aimed to develop visual perception and geometric reasoning in students of 5 th year of Elementary School with the support of Van Hiele Theory, in Santa Maria, RS. This is a qualitative research with a case study and it is anchored in this theory to the development of reasoning in geometry, whose first level (visualization) is useful for the identification of plane and spatial geometric forms. In addition, visualization is ability and current theme in research in Mathematics Education. The second level (analysis)together with the first, were analyzed in an activity in which the researcher used concrete material resources for students to use touch to identify, classify and represent plane and spatial geometric forms. The results showed that the students were able to visualize (such as mental construct) the spatial geometric forms that were in an opaque box, just using touch. From that, identify planes and spatial elements that constituted, named objects and their components and subsequently made their representations in the plane. It was concluded that the activity provided recognize the initial of the teacher about the theory of Van Hiele - visualisation or recognition-for some and development for others, promoting the development of the program of the series / year in sequence.

Keywords: Geometric thinking; Visual abilitie; Geometry; Van Hiele Theory 


\section{Introdução}

O presente artigo traz um recorte da dissertação ‘Espaço e Formas: explorando a Teoria de Van Hiele para ensinar Geometria', realizada pela primeira autora e orientada pelo segundo. A pesquisa teve como objetivo desenvolver percepção visual e raciocínio geométrico em alunos de um $5^{\circ}$ ano do Ensino Fundamental com suporte da Teoria de Van Hiele, da cidade de Santa Maria, RS.

Por se tratar de uma pesquisa realizada com um grupo bem definido e estudar um fenômeno específico, se caracteriza como estudo de caso, segundo Sturman (1988, apud Moreira, 2011, p.86). A natureza é qualitativa ou naturalista de acordo com Moreira (2011), por não envolver manipulação de variáveis e, teve como participantes trinta alunos. A revisão de literatura baseou-se em livros; artigos; dissertações e teses sobre o ensino da Geometria nos anos iniciais do Ensino Fundamental; análise de diferentes conceitos de visualização; ideias de representação em Geometria; teoria de Van Hiele; uso de material manipulável; jogos e sobre o uso da fotografia em sala de aula.

As atividades desenvolvidas foram separadas em dois blocos, de acordo com os dois primeiros níveis de Van Hiele: $1^{\circ}$ ) visualização ou reconhecimento, no qual as figuras são identificadas por sua aparência global; $2^{\circ}$ ) análise, em que as figuras são vistas pelos seus componentes, propriedades e uso dessas para resolver problemas.

A observação, pela professora investigadora, em sala de aula, seu diário de bordo, os registros das representações dos sólidos feitas pelos alunos, o preenchimento por eles das fichas de comparação e as fotografias obtidas durante a realização das tarefas, subsidiaram a construção dos dados, os quais foram posteriormente analisados.

Neste recorte damos destaque a uma das atividades propostas e analisadas na dissertação, a qual desenvolveu a percepção visual e o raciocínio geométrico. Segundo os Parâmetros Curriculares Nacionais - PCN (BRASIL, 1997, p.39) "os conceitos geométricos constituem parte importante do currículo de Matemática no ensino fundamental, porque, por meio deles, o aluno desenvolve um tipo especial de pensamento que lhe permite compreender, descrever e representar, de forma organizada, o mundo em que vive". A Geometria merece destaque por parte dos professores, visto que ela desenvolve o raciocínio visual e facilita a resolução de problemas em diversas áreas do conhecimento.

O artigo apresenta os seguintes tópicos: o ensino de Geometria; visualização e representação; a teoria de Van Hiele; o uso de material manipulável; atividade desenvolvida; conclusões e referências.

\section{$2 \mathrm{O}$ ensino da Geometria}

Os PCN (BRASIL, 1997) orientam para a importância do ensino da Geometria no Ensino Fundamental, por contribuir para o aluno desenvolver uma melhor percepção do mundo em que vive, destacando a sua relevância desde o início da escolarização. Desse modo o ensino da Geometria deve proporcionar ao educando momentos que o leve a desenvolver habilidades espaciais e estimulá-lo a compreender, descrever e representar o espaço que o cerca, observando semelhanças, diferenças e regularidades, além de construir outras relações pertinentes. Portanto, ao trabalhar com a Geometria no Ensino Fundamental, pode-se desenvolver habilidades e competências relacionadas ao pensamento geométrico, tais como, espaço e forma.

Desse modo, é pertinente trabalhar com situações de aprendizagem que levem o aluno a estabelecer relações entre figuras espaciais e suas representações planas, envolvendo sua observação sob diferentes pontos de vista, construindo e interpretando suas representações. Conforme Brasil (1998), ao se fazer a representação plana das figuras espaciais, a principal função é visualizar, provar e fazer conjecturas, sendo assim:

quando os alunos têm de representar um objeto geométrico por meio de um desenho, buscam uma relação entre a representação do objeto e suas propriedades e organizam o conjunto do desenho de uma maneira compatível com a imagem mental global que têm do objeto. [...] A dificuldade dos alunos é a de encontrar articulações entre as propriedades que ele conhece e a maneira de organizar o conjunto do desenho, pois ele deverá escolher entre sacrificar ou transformar algumas delas, como o desenho das figuras tridimensionais. (BRASIL, 1998, p. 125-126).

Todos esses elementos desenvolvidos por meio da Geometria se constituem em partes integrantes do pensamento geométrico, o qual envolve trabalhar com a visualização e representação de figuras geométricas. Com a Geometria, na construção das habilidades visuais, os estudantes podem desenvolver a autonomia de pensamento e raciocínio, desvinculando-se daquele método pronto, típico de reprodução. Desse modo, apresentam-se, a seguir, alguns aspectos sobre visualização e representação de figuras geométricas. 


\section{Visualização e Representação}

A visualização é um tema atual de pesquisa em Educação Matemática e vem sendo tratada há muito tempo, por meio de diferentes enfoques e associada a vários conteúdos e em vários níveis de escolaridade, por diferentes autores Presmeg (1986), Fischbein (1987), Arcavi (1999), Borba e Villarreal (2005), Yin Ho (2008), dentre outros. Leivas (2009), após seus estudos, conceitua visualização como sendo "um processo de formar imagens mentais, com a finalidade de construir e comunicar determinado conceito matemático, com vistas a auxiliar na resolução de problemas analíticos ou geométricos" (p. 111). O autor amplia o sentido do termo ao afirmar que entende

[...] visualização não como uma forma de representação em termos de uma figura ou representação de um objeto e sim como um processo capaz de auxiliar na construção do fazer matemático, bem como na comunicação dos conceitos nas diversas áreas desse conhecimento matemático. (LEIVAS, 2009, p.136).

Afirma ainda que, em seu entendimento, o auxílio visual geométrico pode ser o elemento a percorrer, de forma interdisciplinar, a Geometria como componente curricular.

Flores (2007, p. 34), em referência ao ensino de Matemática, afirma que "a visualização não é como um fim em si mesma, mas um meio para o entendimento de conceitos matemáticos". A autora observa que "esta intimidade entre a visualização e a Geometria não se restringe ao espaço da sala de aula, tampouco às questões atuais" (p. 17). Para a autora, o problema da visualização de figuras geométricas tem início "[...] na compreensão do como e de onde surge nosso modo de olhar e de representar as figuras geométricas, para daí pensar a educação do olhar no ensino de Geometria" (p.27). Desse modo, a Geometria exige a atividade do olhar com o entendimento de que uma imagem desenhada em um plano é a representação de um objeto tridimensional. É possível notar, de certa forma, que não há uma linearidade ou uniformidade no modo como autores tratam a questão da visualização.

Neste sentido Flores, Wagner e Buratto (2012) publicaram resultados de uma pesquisa em que realizam um levantamento bibliográfico tendo os anais do Encontro Nacional de Educação Matemática-ENEM como fonte de dados. O objetivo consistiu em classificar as tendências na pesquisa brasileira sobre visualização na Educação Matemática. Com base nesse estudo, os autores identificaram que o conceito de visualização empregado nas pesquisas é percebido como

processo de construção e transformação de imagens visuais mentais; uma atividade cognitiva que é intrinsecamente semiótica; processo de formação de imagens (mentais, com lápis e papel, ou com o auxílio de tecnologias) e utilização dessas imagens para descobrir e compreender matemática; forma de pensamento que torna visível aquilo que se vê, extraindo padrões da representação. (FLORES et al., 2012 p. 40).

Em termos de representação, há de se considerar a construção do conhecimento geométrico desde a infância, quando começam as primeiras representações. Assim, o desenho construído pelas crianças é uma representação, isto é, supõe a construção de uma imagem distinta da percepção. Piaget e Inhelder (1993) observaram que as primeiras descobertas geométricas da criança são topológicas, o que significa que independem de medidas, como é no caso da Geometria Euclidiana, e que ocorrem espontaneamente nas relações espaciais. Assim, a tomada de consciência das propriedades geométricas se apoia sobre as propriedades que o objeto possui, tais como: formas, dimensões, posições, deslocamentos, entre outros. Mais além, os autores afirmam que "a percepção e a representação do espaço perceptivo são construídas muito mais rapidamente do que o espaço representativo, isso acontece devido à percepção ser constituída em contato direto com o objeto à medida que a imagem intervém em sua ausência" (p. 471). Por esta razão, os autores recomendam que o ensino de Geometria deveria começar pela Geometria Topológica e não pela Euclidiana.

Duval (apud FLORES, 2007, p. 21), afirma que o relacionamento entre uma figura real com sua representação está na complexidade que existe entre a coordenação dos registros de representação presentes na atividade de leitura e interpretação destas figuras, sobretudo no tratamento que vai ao encontro da articulação entre as dimensões bidimensionais e tridimensionais, ou seja, entre a articulação da figura no espaço e sua representação.

Silva (2013) realizou investigação em que propunha verificar como um estudante com cegueira total utilizava materiais concretos para desenvolver habilidades visuais a respeito de figuras geométricas planas e espaciais, explorando conceitos, propriedades e classificações diversas. Marin (2013) utilizou a Geometria Dinâmica do Cabri 3D para concluir que alunos do Ensino Médio apresentaram melhor rendimento, com uso deste software, na visualização de cortes em cubos por planos, do que quando utilizavam representações com lápis e papel.

A partir das ideias expostas no presente texto é possível verificar que visualização e representação são dois elementos indissociáveis, importantes para a formação do pensamento geométrico. 


\section{A Teoria de Van Hiele}

A teoria de Van Hiele teve origem na Holanda quando o casal de professores de Matemática Pierre Marie Van Hiele e Dina Van Hiele-Geldof, apresentaram em suas teses de doutorado, no final da década de 50, na universidade de Utrecht, um modelo de ensino e aprendizagem de Geometria e idealizaram uma nova forma de enfocar o seu desenvolvimento no raciocínio. Eles desenvolveram esta teoria a partir das frustrações, tanto deles quanto dos seus alunos, vivenciadas na relação ensino aprendizagem de Geometria. O modelo de aprendizagem de Van Hiele se baseia na ideia de que o pensamento geométrico se desenvolve em cinco níveis, de forma sequencial e hierárquica, desde a primeira relação com figuras geométricas até a compreensão de provas e demonstrações geométricas.

Os níveis de Van Hiele são: Nível Básico: Reconhecimento ou Visualização; Nível 1: Análise; Nível 2: Síntese ou Abstração; Nível 3: Dedução e Nível 4: Rigor. De acordo com Fantinel (1998), para que haja o avanço de um nível para o próximo, a teoria de Van Hiele ${ }^{1}$ estabeleceu cinco Fases de Aprendizagem que devem ser vivenciadas pelos alunos, as quais são: Fase 1: Interrogação ou Informação; Fase 2: Orientação Dirigida; Fase 3: Explicação; Fase 4: Orientação livre e Fase 5: Integração.

Nasser (1997) afirma que cada nível é caracterizado por relações entre os objetos de estudo e linguagem própria. Consequentemente, não pode haver compreensão quando o curso é dado num nível mais elevado do que o atingido pelo aluno. Crowley (1994) afirma que, para os Van Hiele, cada nível tem seus próprios símbolos linguísticos e seus próprios sistemas de relações que ligam esses símbolos.

Com exceção da fase cinco, as demais podem ocorrer em diversas ordens e até mesmo simultaneamente. Ao final da fase cinco, os alunos devem ter alcançado um novo nível de pensamento, estando assim aptos a repetirem as fases de aprendizagem no nível seguinte. Para Van Hiele, o avanço de um nível para outro não é um processo natural. O professor é a peça chave para auxiliar o aluno no seu desenvolvimento por meio de um programa adequado de ensino-aprendizagem.

\section{0 uso de material manipulável}

Sob a ótica de Reys (apud Passos, 2004, p. 2), os materiais manipuláveis podem ser conceituados como "objetos ou coisas que o aluno é capaz de sentir, tocar, manipular e movimentar. Podem ser objetos reais que têm aplicação no dia a dia ou podem ser objetos que são usados para representar uma ideia".

Desse modo, os materiais manipuláveis podem ser utilizados como contribuição para o desenvolvimento da capacidade de visualização. Assim, é fundamental trabalhar com modelos que representem os sólidos que estão sendo estudados, para que os alunos se familiarizem e formem imagem mental dos mesmos. A utilização de modelos concretos permite que a figura geométrica possa ser observada em várias posições e angulações, tornando o registro da imagem mental mais dinâmico e, com isso, o aluno poderá explorar melhor as propriedades do objeto, fazer conjecturas e tirar conclusões sobre o mesmo.

O recorte da pesquisa constante no presente artigo buscou amparo em recursos táteis, a exemplo do que consta da pesquisa de Silva (2014) com indivíduos em situação de cegueira, porém com recursos materiais diferenciados. Desta feita, somente sólidos geométricos foram disponibilizados para os alunos explorarem em uma caixa opaca sem os terem visto ou terem conhecimento prévio dos objetos que estavam contidos nela. Acreditou-se que, ao se apresentar os sólidos aos alunos, em uma caixa, os quais não poderiam ver concretamente, proporcionaria o construto mental que a investigadora desejava, ou seja, visualização no sentido apontado por Leivas (2009), dentre outros autores mencionados.

\section{Atividade desenvolvida}

Para a realização da atividade, que se escolheu para descrever neste artigo, optou-se por uma turma em que a investigadora era a professora efetiva. Em virtude de estar realizando uma pesquisa para efeito de uma dissertação de mestrado, todos assinaram, livre e espontaneamente, um termo de consentimento. Considerando que a professora utiliza com frequência atividades em grupo, optou-se por esta forma de trabalho e, assim, dividiu-se a turma em cinco grupos de seis alunos cada. A partir do trabalho de Becker (2009), se optou pela construção de uma caixa opaca, contendo um orifício em duas de suas faces laterais opostas, nos quais poderiam introduzir uma mão em cada. Foram colocados previamente objetos em formatos geométricos para se realizar as atividades. Foi entregue a cada grupo uma caixa com objetos diferentes, conforme a Figura 1, e dentro se encontrava um poliedro.

1 Doravante se indicará Van Hiele para a teoria e não para o casal. 


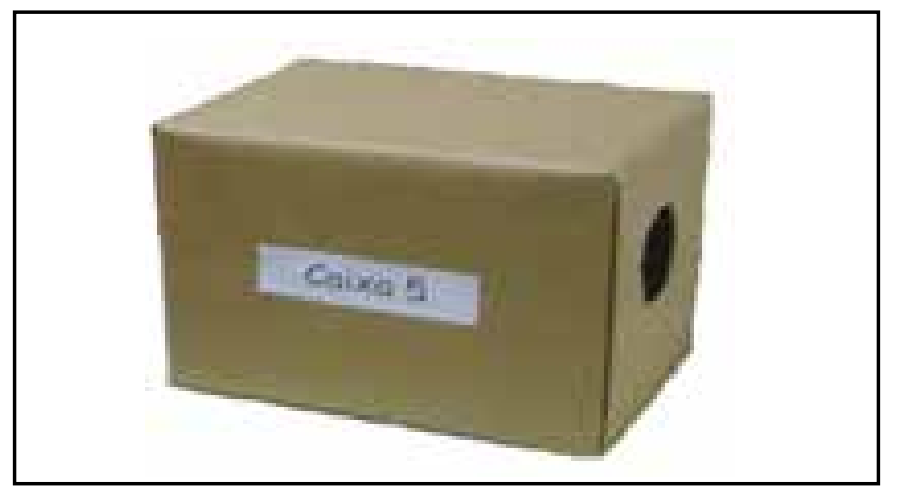

Figura 1 - Caixa utilizada na atividade 1

Fonte: construção de autoria própria da investigadora

Em cada caixa foi colocado, na ausência dos alunos, um poliedro diferente. Foi pedido que um aluno de cada um dos grupos colocasse a mão dentro da caixa, tocasse o sólido e, sem vê-lo, o representasse em forma de desenho, após discussão com os componentes daquele grupo. Por ser inviável a construção de uma caixa para cada um dos alunos, além de não permitir a troca de informações com o colega, foi proposta a atividade em grupo. Dessa forma, poderiam dialogar e discutir entre si para a obtenção de informações que levassem à representação. Há de se considerar que os alunos, em geral, chegam a esse nível de escolaridade sem conhecimentos sobre geometria espacial.

Esta atividade vai ao encontro do que afirma Leivas (2009) no que diz respeito à imaginação e percepção. Há várias formas em que a percepção pode contribuir para o desenvolvimento da imaginação e uma delas pode ser a percepção tátil, na qual o indivíduo, em contato com um determinado objeto, sem visualizá-lo, cria uma imagem mental dele por meio de descobertas exclusivamente táteis, ideia corroborada por Silva (2014) em sua pesquisa com indivíduos em situação de cegueira.

Na Figura 2 tem-se a representação de um cubo feita pelo aluno A13, após ter tocado o sólido dentro da caixa, sem o ter visto previamente. Pode-se observar que esse registro traz todas as faces, arestas e vértices de um cubo, o que mostra uma representação fiel do sólido tocado pelo aluno, salvo o fato de que as arestas ocultas deveriam estar representadas por linhas tracejadas, mas o que não denigre a representação pelo nível de escolaridade em que os alunos deste grupo se encontram. O símbolo no canto superior frontal traduz tal fidelidade uma vez que o objeto possuía um furo destinado à introdução do material destinado à atividade com volume. Acredita-se que a representação, estando ausente da percepção visual do aluno, reitera o preconizado por Piaget e Inhelder (1993), a saber: o sólido escolhido pelo aluno deste grupo foi um cubo que apresentava um pequeno orifício próximo a um vértice, o qual ele representa sem a perna do detalhe. Na observação da professora registrada em seu diário está o debate entre os componentes a respeito do que o A13 informava ter tocado e se isto deveria ser representado. O grupo decidiu que deveriam ser registrados todos os detalhes constatados.

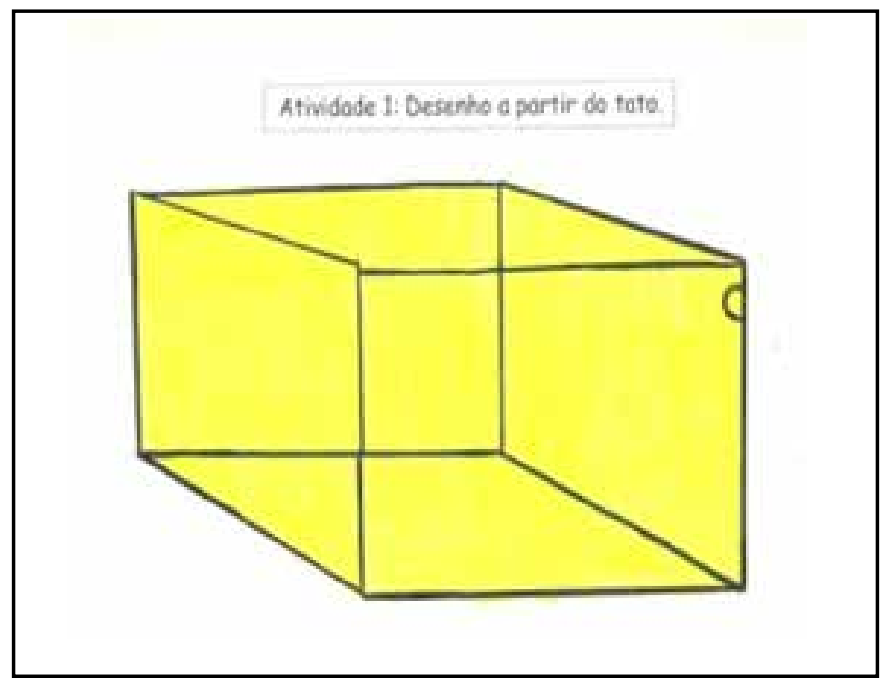

Figura 2 - Representação feita pelo aluno A13

Fonte: arquivo da pesquisadora 
Já na Figura 3, tem-se a representação de um cone feito pelo aluno A10. Nela, constata-se que o cone está representado como um triângulo, o que registra a dificuldade desse aluno em representá-lo a partir do tato, juntamente com seu grupo. Entretanto, poder-se-ia intuir que este aluno (grupo) tivesse o sentido de representação de vistas de um objeto, o que não é próprio deste nível de escolaridade. Em tal situação, se concluiria que a figura está representando a vista frontal do cone. Em observação feita pela professora durante o debate entre os componentes do grupo ficou evidente a dúvida quanto ao objeto que A10 descrevia pelo tato com o mesmo. Observa-se a tentativa de arredondamento nos cantos da borda inferior, o que pode denotar certo conflito entre o percebido e o representado.

Com este registro fica evidente a necessidade de trabalhar visualização de modo a desenvolver a percepção do aluno que não tem essa habilidade e uma das opções que se indicou com a atividade foi o construto mental por meio do tato que, no primeiro nível da teoria de Van Hiele, consiste no reconhecimento do objeto a partir de sua aparência global o que se acredita ter alcançado com a representação do objeto sem o ver. Kaleff (2003) demonstra esta preocupação quando afirma que as informações visuais são importantes tanto para a formação do educando quanto para sua educação global, e, ainda, que tal habilidade é tanto quanto a de calcular numericamente e a de simbolizar algebricamente.

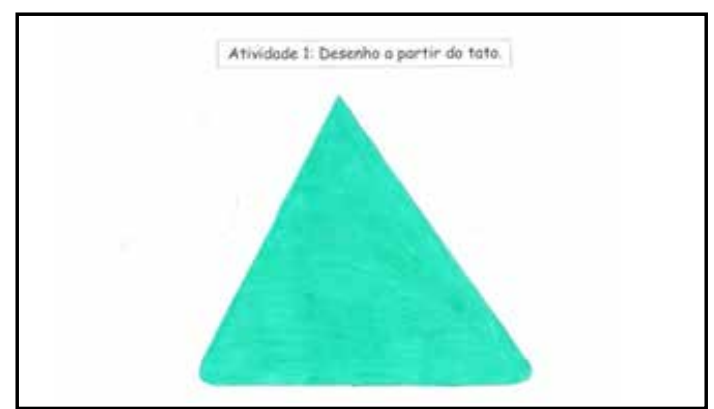

Figura 3 - Representação feita pelo aluno A10

Fonte: arquivo da pesquisadora

Em se tratando de pensamento visual, algumas pesquisas articulam esta ideia à concepções de desenho e suas técnicas. Por exemplo, a ideia apresentada por Silva (2007) aponta o desenho como estruturante ao pensamento visual, como parte de uma interpretação, a qual expressa novas percepções e compreensões. A autora afirma que o desenho é um reflexo do que o aluno conseguiu perceber, compreender e interpretar. Isso reitera a observação feita a respeito da representação e do pensamento visual do aluno A10 na Figura 3.

Deste modo, cada aluno deve ter uma interpretação diferente da outra, fato que explica as várias formas utilizadas pelos alunos, de um mesmo grupo, para representar um mesmo sólido geométrico. Este fato pode ser analisado no registro da Figura 4, onde o aluno A11 representa o paralelepípedo de forma fiel, demonstrando ter habilidades de visualização. Já na Figura 5, o paralelepípedo é representado por um retângulo (aluno A24).

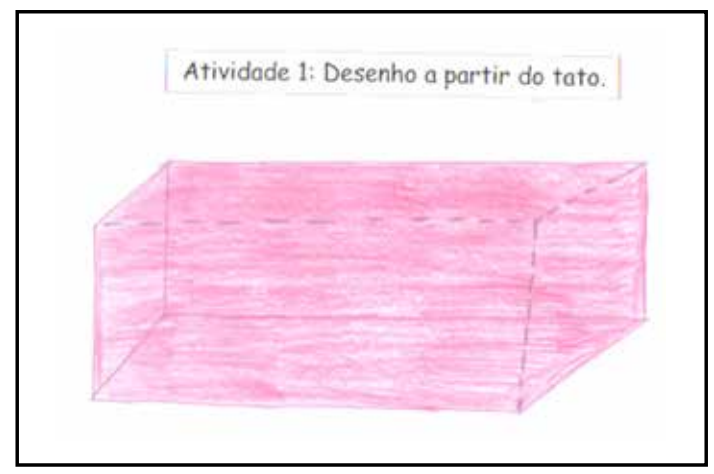

Figura 4- Representação feita pelo aluno A11

Fonte: arquivo da pesquisa

Os demais grupos elaboraram as representações dos sólidos de forma coerente com o que se encontrava na caixa, demonstrando terem construído sua imagem, sem vê-lo, ou seja, apresentam visualização no sentido apontado por Passos (2000) que afirma: “Visualização é a habilidade de pensar, em termos de imagens mentais (representação mental de um objeto ou de uma expressão), naquilo que não está ante os olhos, no momento" (p.80). Como aproximadamente $70 \%$ dos alunos representaram, de forma coerente com a observação tátil, o objeto que lhe havia sido designado, considera-se que o objetivo da questão foi atingido. 


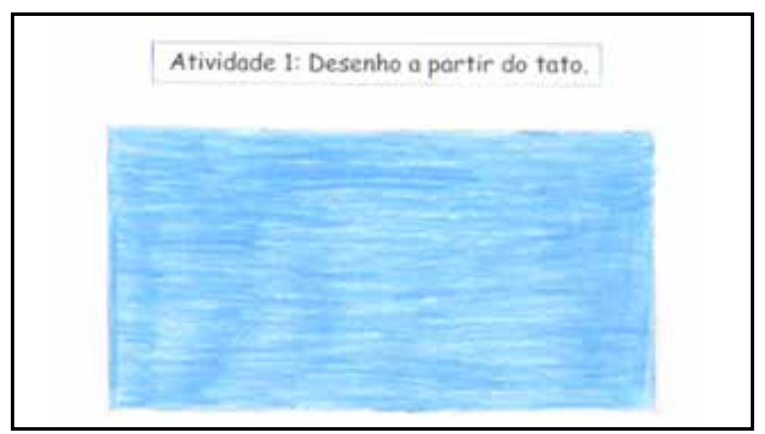

Figura 5 - Representação feita pelo aluno A24

Fonte: arquivo da pesquisadora

Ao concluírem, alguns alunos colocaram o nome de alguns sólidos ao lado da representação realizada, sendo que não foi feito nenhum comentário pela investigadora a respeito da nomenclatura, o que mostrou que alguns deles já os conheciam. Após todos concluírem a tarefa, os sólidos foram retirados das caixas para que os comparassem com seus desenhos. Deve-se considerar que objetos geométricos são, de alguma forma, de conhecimento de alunos desde os primeiros anos, adquiridos por meio de revistas, desenhos animados, filmes. No entanto, os aspectos formais geométricos só vão sendo adquiridos e aprimorados no transcorrer da escolaridade e constam dos planos curriculares da série em que a pesquisa foi realizada. Assim, as atividades desenvolvidas tornaram-se motivadores para a continuidade do desenvolvimento do conteúdo programático de Geometria.

De acordo com os PCN, Brasil (1998, p. 51), “O trabalho com espaço e forma pressupõe que o professor de Matemática explore situações em que sejam necessárias algumas construções geométricas com régua e compasso, como visualização e aplicação de propriedades das figuras, além da construção de outras relações". Entende-se que a atividade proporcionou à professora compreender que os alunos conseguiram trabalhar na fase 2 da teoria de Van Hiele, que é a de orientação dirigida, na qual os alunos exploram o tópico de estudo por meio de materiais selecionados cuidadosamente pelo professor e que as atividades devem revelar, gradativamente, aos alunos as estruturas características do nível.

A partir das duas atividades aqui relatadas foi possível concluir que a teoria de Van Hiele pode ser uma aliada metodológica consistente ao professor pois permite retomar conhecimentos que alguns alunos já possuem e reorganizá-los com fundamentação teórica adequada de acordo com o nível de escolaridade em que se encontram. Por outro lado, possibilita ao professor planejar sua disciplina de modo a resgatar os que não estão em determinado nível e avançar para subsequentes, seguindo uma das características da teoria que é a sequencialidade.

Retoma-se o que indicam os PCN, Brasil (1998, p.73) "classificação de figuras tridimensionais e bidimensionais, segundo critérios diversos, como: corpos redondos e poliédricos; regulares e não regulares; prismas, pirâmides e outros poliedros [...]" para amparar a proposição da atividade aqui descrita. O referido documento recomenda que, no último ciclo do Ensino Fundamental, no bloco Espaço e Formas, seja feita "[...] representação de diferentes vistas (lateral, frontal e superior) de figuras tridimensionais e reconhecimento da figura representada por diferentes vistas." (Ib. p. 88). Portanto, a atividade pode ser considerada como relevante para a formação geométrica desses alunos quando chegarem ao referido ciclo.

Foi objetivo da pesquisa de mestrado analisar o bloco Espaço e Formas em uma série específica do Ensino Fundamental e o recorte da dissertação aqui apresentado centrou-se naquelas que abordariam o nível 1 da teoria de Van Hiele, tendo-se visualização como uma característica desse nível o que julga-se que os indivíduos tenham adquirido, ou seja, um construto mental, como indicado por Leivas (2009) e que se encontra presente ao internalizarem a imagem do objeto geométrico sem vê-lo e o transferirem para uma representação por desenho, o que é reiterado em Passos (2000) ao assumir visualização como sendo a habilidade de pensar e transformar conceitos abstratos em imagens reais ou mentalmente visíveis.

Na sequência da pesquisa, a segunda atividade consistiu na construção e comparação de sólidos em que os alunos os construíam a partir das planificações e os comparavam com objetos que encontravam em seus cotidianos. Eles deveriam tentar identificar o sólido planificado, os quais eram todos os que estavam contidos nas caixas da atividade 1 . Somente após deveriam recortar e montar.

A terceira atividade teve como objetivo elaborar características de comparação dos elementos de um mesmo grupo de sólidos geométricos fornecidos, por meio de características comuns como forma, tamanho, ou outra especificação que julgassem pertinente. A quarta atividade foi uma sequência da anterior e teve por objetivo analisar semelhanças e diferenças entre os sólidos com cada característica explicitada anteriormente. Nessa atividade a professora investigadora promoveu debate com o grupo todo, para formalizar no quadro as conclusões dos grupos, o que lhes permitiu realizarem passagem a novo nível. 
A quinta atividade teve por objetivo identificar e desenhar uma figura a partir de pistas verbais de suas propriedades, pela professora investigadora. Esta fornecia uma pista verbal de uma figura e o aluno identificava em uma ficha possibilidades do sólido que tivessem tal característica até o primeiro grupo identificá-la. Isso foi feito com os seis sólidos: cubo, cone, esfera, cilindro, paralelepípedo e pirâmide. A penúltima atividade consistiu em investigar propriedades dos sólidos a partir de pistas visuais. Para isto a investigadora ia desvelando gradativamente um dos sólidos, os alunos identificavam prováveis nomes em cada estágio desvelado até chegar à figura.

Na finalização das atividades foi feito um jogo para identificar propriedades e classes de figuras geométricas, utilizando cartas contendo afirmações e perguntas. Espera-se produzir novos artigos a partir da análise dos dados da realização dessas atividades, pois não caberia num único artigo, com limitação de texto.

\section{Conclusão}

A aprendizagem de Geometria, no Ensino Fundamental, geralmente acontece pelo método tradicional, basicamente pelos recursos lápis e papel, giz e quadro, livro-didático e exposição oral do professor. Essa forma de conduzir o ensino é favorável apenas para o desempenho dos alunos que possuem facilidade em visualização e representação de figuras geométricas, porém outros alunos que, necessitam desenvolvê-las, já não terão o mesmo desempenho.

A diversificação de práticas metodológicas, como as aplicadas nas pesquisas de Marin (2013), De Paula (2015), Oliveira (2015), para a aprendizagem da Geometria, torna as aulas mais agradáveis e as dificuldades desta disciplina poderão ser amenizadas, como tais pesquisas concluiram. Particularmente, o recorte da dissertação apresentado neste artigo, na atividade em que os alunos necessitavam identificar um sólido geométrico, a partir do contato com uma coleção de materiais concretos, que não se encontravam sob seus olhares, mostrou ser viável de ser aplicado. A atividade despertou interesse da turma, o espirito investigativo, a descrição verbal e a representação do sólido, com a exploração de suas características como arestas, vértices, faces, fazendo emergir propriedades e nomenclaturas até então não formalizadas no âmbito escolar.

Do objetivo geral da pesquisa, de desenvolver percepção visual e raciocínio geométrico em um grupo de alunos de um $5^{\circ}$ ano do ensino fundamental e, dos dados coletados na atividade 1 , recorte da dissertação e constante do presente artigo, percebe-se que alguns alunos, por exemplo, A13 e A11, se destacaram pela facilidade em visualizar e representar os objetos geométricos que recolheram da caixa, ou seja, facilmente se encontram no nível da visualização ou reconhecimento da teoria de Van Hiele. Além disso, conseguiram identificar algumas propriedades dos objetos bem como estabelecer relações o que pode indicar que provavelmente podem passar ao segundo nível sem maiores dificuldades.

Outros alunos da turma apresentaram dificuldades, como é o caso de A10 e A24. Assim, de acordo com a teoria, não devem avançar para o segundo nível sem adquirir os aspectos característicos deste nível, ou seja, visualizarem sólidos geométricos a partir de sua aparência e características globais. Portanto, se faz necessário realizar outras atividades diversificadas que os habilite a progredir no seu desenvolvimento do raciocínio em Geometria, a qual, sendo trabalhada de forma mais lúdica e prática, pode proporcionar melhoria na sua aprendizagem, o que foi constatado ao final da investigação realizada no mestrado. Há de se considerar que não houve troca de caixas entre os grupos de modo que, cada um representou o sólido da caixa que havia sido designada e, portanto, não seria possível identificar se A10 e A24 conseguiriam representar outro sólido, não sendo este o objetivo da atividade.

Ao trabalhar o conteúdo de Espaço e Formas, de um modo diferenciado, realizou-se atividades lúdicas e com material concreto, as quais proporcionaram aos alunos um aprendizado mais significativo, como pode ser observado na evolução do alcance de níveis mais elevados da teoria de Van Hiele e o cumprimento das fases do primeiro nível pela maioria dos alunos, o que consta na dissertação.

Na primeira atividade aplicada foi proposto que os alunos, ao tocarem um objeto escondido dentro de uma caixa, tivessem uma percepção tátil do sólido e, consequentemente, os que não possuíam habilidades visuais a adquirissem, não pelo órgão da visão e sim como construto mental, como apontado por autores citados, pois, ao tocá-lo, eles imaginam esse sólido e suas partes. Logo após tocá-los os alunos fizeram sua representação em folha de desenho e, assim, certifica-se que se encontravam no primeiro nível de Van Hiele, uma vez que, no primeiro nível do pensamento geométrico, o indivíduo "vê" o sólido apenas pela sua aparência global.

Observando-se os resultados obtidos, percebe-se que essa atividade auxiliou a grande maioria dos alunos no desenvolvimento de sua capacidade de visualização geométrica e representação de objetos tridimensionais no plano, uma vez que aproximadamente $70 \%$ dos envolvidos representaram corretamente as figuras que haviam identificado pelo tato. Além disso, aproximadamente $60 \%$ dos alunos, registraram os nomes dos sólidos corretamente, o que é bastante significativo pois os mesmos ainda não haviam, ainda, desenvolvido este conteúdo de maneira formal, e isso permitiu dar continuidade ao desenvolvimento do conteúdo. Na sequência da pesquisa outras atividades foram aplicadas e puderam comprovar os avanços dos alunos para níveis subsequências da teria utilizada. 
Para finalizar, a professora aplicou, posteriormente, na avaliação trimestral, atividades relacionadas com as da pesquisa, tendo comprovado que $92 \%$ da turma as realizou de forma correta, o que demonstrou ter sido produtiva a aplicação da teoria de Van Hiele para a turma, especialmente considerando resultados obtidos em anos anteriores sem esta metodologia de ensino. Por outro lado, nessa avaliação, houve uma pergunta sobre as impressões que os alunos tiveram sobre o tipo de metodologia utilizada e se gostariam de que fosse aplicada em outros assuntos. Os registros mostraram satisfação, prazer, interesse pela matéria e gostariam que outras partes do conteúdo deveriam ser realizadas assim.

\section{Referências}

ARCAVI, A. The role of visual representation in the learning of mathematics. In: NORTH AMERICAN CHAPTER OF THE PME, 1999. Proceedings... Disponível em: <http://www.clab.edc.uoc.gr/aestit/4th/PDF/26. pdf>. Acesso em: 30 set. 2015.

BORBA, M.C.; VILLARREAL, M.E. Humans-with-media and the reorganization of mathematical thinking: information and communication, technologies, modeling, experimentation and visualization. New York: Springer, 2005.

BRASIL. Secretaria de Educação Fundamental. Parâmetros Curriculares Nacionais: matemática. Brasília: MEC/SEF, 1997.

BRASIL. Ministério da Educação Fundamental. Parâmetros Curriculares Nacionais: Matemática. Brasília: MEC/ SEF,1998.

CROWLEY, M. L.O modelo Van Hiele de desenvolvimento do pensamento geométrico. In: LINDQUIST, M.; SHULTE, A. (orgs). Aprendendo e ensinando geometria. Tradução de Hygino Domingues. São Paulo: Atual,1994.

DE PAULA, S. F. Materiais manipuláveis para o aprendizado do princípio de Cavalieri. Dissertação (Mestrado Profissional em Ensino de Matemática). Disponível em http://wwww.unifra.br/site/pagina/conteudo/51\#. Acesso em 10 out. 2016.FANTINEL, P. C. Representações gráficas espaciais para o ensino de cálculo e álgebra linear. Rio Claro: Unesp, Dissertação de Mestrado,1998.

FISCHBEIN, Efraim. Intuition in science and mathematics: an educational approach. Dordrecht: Reidel, 1987.

FLORES, C. R.; WAGNER, D. R.; BURATTO, I. C. F. Pesquisa em visualização na educação matemática: conceitos, tendências e perspectivas. Revista Educação Matemática e Pesquisa. v. 14, n. 1, p. 31-45, 2012.

FLORES, C. R. Olhar, saber, representar: sobre a representação em perspectiva. São Paulo: Musa Editora,2007.

KALEFF, A.M. Vendo e entendendo Poliedros: do desenho ao cálculo do volume através de quebra-cabeças geométricos e outros materiais concretos.2.ed. Niterói: EDUFF, 2003.

LEIVAS, J. C. P. Imaginação, Intuição e Visualização: a riqueza de possibilidades da abordagem geométrica no currículo de cursos de Licenciatura em Matemática. Tese (Doutorado em Educação, UFPR), Curitiba, 2009, 294p.

MARIN, G.B. O Software Cabri 3D como ferramenta de auxílio ao ensino e visualização de secções planas no cubo para alunos do Ensino Médio. Dissertação (Mestrado Profissionalizante em Ensino de Matemática). Disponível em http://wwww.unifra.br/site/pagina/conteudo/51\#. Acesso em 10 out. 2016.

MOREIRA, M.A. Metodologias de pesquisa em ensino. São Paulo: Editora Livraria da Física, 2011.

NASSER, L. SANT'ANNA, N.F.P (coordenadoras). Geometria segundo a teoria de Van Hiele. Instituto de matemática - UFRJ. Projeto Fundão. Rio de Janeiro, 1997.

OLIVEIRA, M. T. Espaço e formas: explorando a Teoria de Van Hiele para ensinar geometria. Dissertação (Mestrado Profissional em Ensino de Matemática). Disponível em http://wwww.unifra.br/site/pagina/ conteudo/51\#. Acesso em 10 out. 2016. 
PASSOS, C. L. B. Recursos Didáticos na Formação de Professores de Matemática. In: VII ENCONTRO PAULISTA DE EDUCAÇÃO MATEMÁTICA: MATEMÁTICA NA ESCOLA: CONTEÚDOS E CONTEXTOS. Anais...São Paulo, 2004. SBEM/SP, 2004. p. 01-11.

PIAGET, J. e INHELDER, B. A. Representação do Espaço na Criança. Porto Alegre: Artes Médicas, 1993.

PASSOS, C.L.B. Representações, interpretações e prática pedagógica: a Geometria na sala de aula. Tese (Doutorado em Educação - UNICAMP). Campinas, 2000, 364p.

PRESMEG, Norma C. Visualization and mathematical giftedness. Educational Studies in Mathematics, v. 17, n. 3 , p. 297-311, 1986.

SILVA, M.de C. Desenho e pensamento: imagem e texto, deslocamentos e cidades. Dissertação de Mestrado/ UFRGS. Porto Alegre, 2007, p. 25.

SILVA, D. C. da. Habilidades visuais desenvolvidas em uma oficina inclusiva de geometria para cegos. In: Vidya, v. 34, n. 1, p. 27-46, jan./jun., 2014

YIN HO, S. Roles of visualization in mathematical problem solving. In: PSYCHOLOGY OF MATHEMATICS EDUCATION, 32, 2008, Morelia, Mx. Anais... Morelia: PME, 2008. v. 1, p. 347 